\title{
O processo de ensino- aprendizagem de leitura e de escrita sob o viés retórico-argumentativo
}

\author{
Aidil Soares Navarro ${ }^{1}$ \\ Fernanda Martin Sbroggio ${ }^{2}$
}

$\mathrm{C}_{\text {processo de ensino-aprendizagem de leitura e escrita no ensino básico. }}^{\text {ste capítulo discorre sobre perspectivas retórico-argumentativas para o }}$ Por ser a escola, e mais precisamente a sala de aula, um espaço comunicativo, no qual as relações são mediadas pela linguagem, as estratégias discursivas e persuasivas postuladas pela retórica podem contribuir para elucidar como se dá a construção desses processos discursivamente.

A retórica aristotélica tinha como foco o emprego da linguagem falada, perante uma multidão reunida em praça pública, a fim de obter a adesão desses espíritos a uma determinada tese, e dessa forma utilizava-se do discurso oral, servindo-se especialmente dos recursos da eloquência e da oratória. A Nova Retórica, de Perelman e Olbrechts-Tyteca (2014), debruça-se sobre a linguagem escrita, preocupando-se mais diretamente com a estrutura da argumentação escrita. Ambas fundamentam as teorias sociorretóricas, de Charles Bazerman (2015), sobre leitura e escrita como atividades sociais situadas, em que a compreensão de gênero é essencial à construção da situação comunicativa pelo escritor e pelo leitor.

$1 \quad$ Mestre em Língua Portuguesa pela PUC-SP, possui graduação em pedagoga, licenciada em História e especialista em Psicopedagogia Institucional e Clinica e Direito Educacional pela Universidade Iguacú, especialista em Metodologia do Ensino Superior pela Fundação Santo André; Membro do Grupo ERA.

2 Mestre em Língua Portuguesa pela PUC-SP, possui graduação em Letras pela Unesp de São José do Rio Preto (2001) e Pedagogia pela Faculdade Soares de Oliveira de Barretos (2011); Membro do Grupo ERA. 
O ensino da leitura e da escrita, por exigir decisões cognitivas complexas e uma série de ações de linguagem, é por si só uma tarefa árdua, mas se revela ainda mais desafiadora quando se consideram todas as demais variáveis nela envolvidas, que compreendem desde a estrutura da escola, os materiais didáticos ofertados até a heterogeneidade social e formativa da comunidade escolar brasileira. Nesse contexto, uma abordagem que pretendesse dar conta de todas essas nuances ou que se propusesse a oferecer receitas milagrosas para execução dessa tarefa poderia revelar-se ingênua e até presunçosa. Por isso, este capítulo apresenta-se como um convite à reflexão sobre o processo de ensino-aprendizagem de leitura e de escrita no ensino básico, com enfoque retórico sobre o auditório e o gênero como conceitos fundamentais para o desenvolvimento do protagonismo do leitor e do escritor.

\section{Atenuação do medo e desenvolvimento do protagonismo do aluno}

"Vais encontrar o mundo, disse-me meu pai, à porta do Ateneu" (POMPÉIA, 1997, p. 30). Essa passagem de O Ateneu, de Raul Pompéia, coloca, oportunamente, a escola como um microcosmo da sociedade, onde estão imbricadas diferenças de ordem religiosa, social e cultural que tornam esse espaço um terreno fértil para os conflitos, divergências de opiniões e de interesses que, em uma comunidade civilizada, são negociados pela linguagem. Essas idiossincrasias interferem no trabalho pedagógico na medida em que influenciam os objetivos de aprendizagem dos alunos e colocam o professor diante do desafio de conciliá-los e de motivar os sujeitos. A escola é um contexto retórico por excelência, por isso as estratégias discursivo-argumentativas postuladas por esta perspectiva discursiva podem contribuir para a negociação das distâncias que se formam nesse ambiente.

A retórica foi conceituada por Aristóteles como "a faculdade de ver teoricamente o que, em cada caso, pode ser capaz de gerar persuasão" (s/d [384-322 a.C.], p. 33), isto é, é a arte de persuadir pelo discurso, levando as pessoas a aderirem a determinada tese. Na perspectiva de Reboul (1998, p. $24)$, a retórica diz respeito à "arte de encontrar meios de persuasão que cada caso comporta", trata-se do uso estratégico do discurso. Para Meyer (2007, p. 25), "a retórica é a negociação da diferença entre os indivíduos sobre uma questão dada". Perelman e Olbrechts-Tyteca (2014, p. 6) preocupam-se espe- 
cialmente com a maneira pela qual se efetua a comunicação com o auditório, já que, para eles, "é em função de um auditório que qualquer argumentação se desenvolve". Como se vê, a retórica não se preocupa em oferecer definições abstratas sobre o código, mas sim em instrumentalizar o usuário da língua de recursos estratégico-argumentativos a fim de que este possa usar as palavras para alcançar seus objetivos em situações concretas de comunicação.

A escrita surgiu, segundo Fischer (2006), aproximadamente em 440 a.C. na Mesopotâmia a partir da necessidade de preservar acordos comerciais, valores de mercadorias, enfim, para atender às demandas práticas da sociedade. Com ela, nasceu também a leitura, que inicialmente se restringia à declamação e à obtenção de informações visuais. Desde então, a relação entre leitura e escrita vem se transformando e modificando a sociedade, que hoje é orientada pelo letramento, cujo principal produto de comunicação é o texto. Mas, apesar de essa relação remontar ao início da civilização humana e de a sociedade estar exposta a inúmeros tipos de texto em circulação, o processo de aprendizagem de leitura e escrita sistematizadas ainda desafia professores, alunos e comunidade científica.

Não se pode negar que a escola tem progredido muito em relação à compreensão desses processos e que procura diariamente lançar mão de pedagogias capazes de tornar o ensino de leitura e escrita mais eficiente. No entanto, apesar de todos os esforços, a conquista da proficiência em leitura e escrita é ainda um processo nebuloso, pelos quais os alunos parecem não se sentir atraídos, o que acaba se evidenciando, entre outros indicadores, pelos baixos índices apontados pelas avaliações do ensino básico.

De modo geral, os estudantes demonstram ainda manter com a leitura uma relação muito pautada na decodificação, o que Leffa (1996) chamou de "leitura extração-de-significado", cuja direção é do texto para o leitor, e o propósito é encontrar o sentido do texto, que possui significado "preciso, exato e completo" (LEFFA, 1996, p. 12). A leitura realizada dessa forma reserva ao leitor um lugar de subordinação ao texto, cujo sentido é extraído palavra por palavra e a compreensão global do texto, assim, a construção do sentido por meio da atuação do leitor não ocorrem. Nesse modelo, a ênfase acaba residindo em aspectos semânticos obtidos a partir da decodificação da língua escrita e da identificação de informações.

Algumas abordagens que buscam explicar o desapreço dos estudantes pelas atividades de produção textual referem-se às situações de escrita altamente monitoradas, que, com um percurso previamente definido, atribuem ao processo certa artificialidade e relegam aos alunos o papel de mero cumpridor de tarefas, inviabilizando sua participação consciente na construção do texto. 
Isso acontece, por exemplo, quando são apresentadas propostas de produção textual com temas distantes da realidade do auditório, ou a partir de gêneros trabalhados apenas como um conjunto de características pré-estabelecidas. Uma tarefa que se apresenta artificial ou distante do sujeito tem uma resposta também artificial, pois o aluno tende a não se envolver e apenas cumprir os requisitos observados na avaliação, que em geral questionam aspectos formais do texto. Por outro lado, atividades de escrita muito livres de orientação causam igual desconforto, pois deixam os estudantes sem saber que direção tomar. Em ambas as situações, as sensações geradas são o medo e a aversão.

Esse cenário aponta para a necessidade de que o aluno assuma o protagonismo no processo de aprendizagem de leitura e escrita, de modo que ele consiga construir o sentido do texto a partir da mobilização das suas experiências e se enxergar como autor da sua produção textual. Para isso, é importante o professor ter em mente o auditório com o qual está trabalhando, a fim de conseguir atingi-lo eficazmente e oferecer a ele situações contextualizadas de leitura e produção textual. Leitura e escrita envolvem, sobretudo, criatividade e protagonismo.

Perelman e Olbrechts-Tyteca (2014, p. 22) afirmam que o "auditório é o conjunto daqueles que o orador deseja influenciar com a sua argumentação". Cabe ao orador pensar nos indivíduos que pretende persuadir a fim de que o auditório presumido seja o mais próximo possível do auditório. A questão retórica é condição básica para o início de qualquer discurso, por isso precisa ser apresentada em função desse auditório de modo que ele se sinta motivado a se envolver e a elaborar uma construção discursiva capaz de intervir nessa questão. De acordo com Reboul (1998, p. 91), "a eficácia do ensino de matemática não se demonstra matematicamente", o que no contexto em que foi empregado ilustra a sua concepção de que entre a demonstração científica e as provas há todo um domínio da argumentação. Esse é um dos pontos em que que se ancora essa reflexão, o exercício docente pode tornar-se ainda mais frutífero à medida que o professor focar no auditório e na organização do seu discurso em função dele.

A reflexão do professor sobre a composição do seu auditório permite a ele localizar o contexto sócio-histórico em que esses indivíduos estão inseridos. Neste momento, emerge o segundo ponto destas considerações: o contexto comunicativo no qual se ancoram as atividades de leitura e escrita.

No ensino de leitura e escrita, o texto é elemento central e sua conceituação pelo interacionismo sociodiscursivo de Bronckart (2012) é o ponto de partida para reflexões aqui propostas sobre o papel do gênero textual na contextualização do ensino de leitura e escrita. De acordo com o autor, o 
texto, em uma primeira acepção, é “toda unidade de produção de linguagem que veicula uma mensagem linguisticamente organizada e que tende a produzir um efeito de coerência sobre o destinatário" (BRONCKART, 2012 , p. 71), ou seja, os textos são produto da atividade humana, "articulados às necessidades, aos interesses e às condições de funcionamento das formações sociais no seio das quais são produzidos" (BRONCKART, 2012, p. 72). Como os contextos sociais são muito diversos, no âmbito de cada comunidade surgem diferentes formas de construção dos textos, organizados por meio da linguagem em função do contexto comunicativo, do propósito da comunicação e do sujeito ao qual ela se destina (auditório). Bronckart (2012) chamou essa variedade textos de "espécies de textos", Bakhtin (1997), de gêneros textuais e Bazerman (2015), de contexto comunicativo, que, para ele, é essencial para o processo de ensino aprendizagem de leitura e escrita.

Os gêneros textuais evidenciam o lugar sócio-histório a partir do qual a escrita e a leitura se desenvolvem e localizam o produtor do texto assim como seu auditório. Como os textos escritos não possuem a interação instantânea da comunicação verbal, pois viajam no tempo e no espaço, a leitura de qualquer texto, para ser significativa, precisa, antes, ser situada, ou seja, os elementos que dela participam precisam ser conhecidos. Essa contextualização é feita pelos gêneros, que para além da forma e do conteúdo, veiculam informações implícitas essenciais ao entendimento do texto. De acordo com Bazerman (2015), os gêneros

corporificam compreensões de situações, relações, posições, humores, estratégias, recursos apropriados, metas e muitos outros elementos que definem a atividade e formam meios de realização. Os gêneros são modos de fazer as coisas - e como tais corporificam o que se deve fazer, trazendo marcas do tempo e lugar no qual se realizam tais coisas, bem como os motivos e ações realizadas nesses lugares. (BAZERMAN, 2015, p. 34-35).

Essa perspectiva aponta para o contexto comunicativo como fator essencial ao trabalho com leitura e produção textual, pois estar em um espaço socialmente reconhecível dá ao aluno o conforto necessário para participar mais ativamente de ambos os processos.

Piovezan (2017, p. 19) considera que "atividades de produção escrita, quando realizadas de forma contextualizada, com propósitos claros e com procedimentos de autoria do aluno" têm como resultado a atenuação, ou até anulação, do medo e favorecem o aprimoramento da escrita, pois um ambiente conhecido ajuda nesse enfrentamento, dá objetivo para a 
construção do texto, determina o auditório e suas prováveis expectativas e possibilita a constituição de um ethos compatível com a situação comunicativa que se apresenta. Nesse sentido, é um dos desafios do trabalho com a escrita reproduzir situações de uso da linguagem nas quais os alunos se reconheçam social e historicamente e assumam o seu protagonismo. $\mathrm{O}$ aluno precisa se sentir convidado para a discussão, precisa acreditar que a sua atuação retórica pode interferir na situação inicial, mas para isso ele deve estar em um ambiente confortável, conhecido, no qual se sinta seguro.

Nessa mesma direção encontra-se o trabalho com a leitura, que é atividade investigativa, da qual o leitor precisa participar ativamente, e que envolve, não apenas o código escrito, mas uma série de informações externas a ele e que são extremamente significativas, como a folha de papel utilizada, a disposição das palavras na página, o tipo de letra, enfim, informações que contribuem para a compreensão do propósito do texto, do seu escritor e do destinatário. Como afirma Bazerman (2015, p. 18), a "interpretação se funda não somente na decifração do código, mas também na construção do contexto de uso dentro do qual o enunciado foi significativo". A identificação do gênero permite ao aluno participar mais ativamente da leitura, pois as informações oferecidas por esse contexto mobilizam a sua atenção, possibilitam um contato mais próximo com o texto, ativam os conhecimentos prévios e suscitam lembranças.

De acordo com Trevisan (1992), a atividade de leitura é apenas o ponto de partida na busca pela compreensão, pois o sentido não está no texto. O leitor e seus conhecimentos prévios têm papel essencial na construção de sentido e coerência de um texto, que só são alcançados à medida que o leitor ativa os seus conhecimentos armazenados e realiza inferências. Nessa mesma página, Kleiman (1989) aponta dois caminhos que conduzem à compreensão na leitura e que também envolvem o trabalho com o contexto comunicativo: a ativação do conhecimento prévio referente ao assunto do texto e o estabelecimento de objetivos e propósitos claros para a leitura. Para ela, a interação dos diversos níveis de conhecimento prévio - linguístico, textual e de mundo - é o que faz da leitura um processo interativo e que permite ao leitor a construção do sentido do texto. De igual importância é o estabelecimento de objetivos e propósitos claros, já que a capacidade de processamento e de memória é significativamente ampliada quando é fornecido um objetivo a uma tarefa. O estabelecimento de objetivos favorece a formulação de hipóteses, ou seja, o leitor ativo vai formulando e testando hipóteses durante a leitura, o que corrobora o entendimento de que o texto não é um produto acabado que o leitor recebe passivamente, 
ao contrário, o leitor precisa envolver-se ativamente na construção da significação e exercer o seu protagonismo.

\section{Considerações finais}

A retórica, entre as ciências que estudam o discurso, possui um caráter prático e ajuda a compreender como as palavras podem ser usadas mais eficazmente para que os propósitos comunicativos sejam alcançados. No percurso aqui apresentado, em que se buscou refletir sobre o processo de ensino-aprendizagem de escrita e de leitura no contexto escolar do ensino básico, as contribuições da sociorretóricas fizeram emergir dois pontos principais que podem contribuir para auxiliar o professor a vencer o desafio de motivar os alunos e torná-los protagonistas nesse processo: a constituição do auditório pelo professor e a contextualização do espaço comunicativo como ponto de partida no trabalho com o texto. Essas duas ações oferecem conforto ao aluno e atenuam seu medo porque localizam o momento da escrita ou da leitura, orientam o processo, fazem surgir compreensões e percepções necessárias ao exercício e não roubam dele o papel da criação. 


\section{Referências}

ARISTÓTELES [384-322 a.C]. Arte retórica e arte poética. Trad. Antônio Pinto de Carvalho. 14 ed. São Paulo; Rio de Janeiro: Ediouro, s/d.

BAKHTIN, M. Estética da criação verbal. Trad. Maria Ermantina Galvão. 3 ed. São Paulo: Martins Fontes, 1997.

BAZERMAN, C. Retórica da ação letrada. Trad. Adail Sobral, Angela Dionisio, Judith Chambliss Hoffnagel, Pietra Cunha. São Paulo: Parábola Editorial, 2015.

BRONCKART, J. Atividade de linguagem, textos e discursos. Por um interacionismo sociodiscursivo. Trad. Anna Rachel dos Santos, Péricles Cunha. 2 ed. São Paulo: EDUC, 2012.

FISCHER, S. R. História da leitura. São Paulo: Unesp. 2006.

KLEIMAN, Â. Texto e Leitor. Aspectos cognitivos da leitura. Campinas, SP: Pontes, 1989.

LEFFA, V. J. Aspectos da leitura. Porto Alegre, Sagra: DC Luzzatto, 1996.

MEYER, M. A Retórica. Trad. Marly N. Peres. São Paulo: Ática, 2007.

PERELMAN, C.; OLBRECHTS-TYTECA, L. Tratado da Argumentação: a nova tetórica. São Paulo: Martins Fontes, 2014.

PIOVEZAN, E. S. O lugar do autor na escola. 2017. Dissertação (Mestrado em Língua Portuguesa) - Pontifícia Universidade Católica, São Paulo.

POMPÉIA, R. O Ateneu. Rio de Janeiro: Ediouro; São Paulo: Publifolha, 1997. REBOUL, O. Introdução à retórica. São Paulo: Martins Fontes, 1998.

TREVISAN, E. Leitura: Coerência e Conhecimento Prévio. Santa Maria: Ed. UFMS, 1992. 

